\title{
A colagem, como estruturadora da imagem da obra dramática de Pablo Picasso: $O$ desejo pego pelo rabo
}

ANA LÚCIA BRASIL MALECHA

This work is dedicated to the study of the correlations between the dramatic and pictoric discourse present in the dramaturgic text of Pablo Picasso The desire caught by the tail. The study aims to analyze the images created by Picasso in his dramaturgic text with the idea of collage as the backbone of his scenic thinking. The understanding of collage, from the idea of shock operated between heterogeneous materials, is the object of investigation and reflection of this research through the images created by Picasso in his theatrical play. The work seeks to analyze this dramaturgic work with the intention of establishing parallels between distinct representative languages.

O estudo em questão pretende analisar algumas imagens cênicas e dramáticas criadas por Picasso em seu texto dramatúrgico $O$ desejo pego pelo rabo (Picasso, 1997), a partir da conceituação de Marjorie Perloff sobre colagem e de algumas obras de colagem de Picasso. A compreensão da colagem a partir da introdução na obra de materiais da experiência cotidiana e o choque operado entre esses materiais heterogêneos é o objeto de investigação e reflexão desse artigo através das imagens criadas por Picasso em sua peça teatral.

O entendimento de que o que dizemos sobre o mundo é em si parte dele mesmo torna-se central para a compreensão da noção de colagem. No caso de Picasso e suas colagens, aplicar à pintura, que é do mundo, as coisas do mundo é entender a pintura como mais um objeto de manipulação, onde as fronteiras entre o simulado e o real ficam removidas criando uma imagem em crise. Esta imagem se caracteriza pela tensão entre elementos contraditórios, estabelecendo o choque e o aspecto de colagem que acabou por caracterizar boa parte da produção artística 
moderna e contemporânea. A imagem tensionada, em crise, traz em si um sentido de colapso, de perturbação da ordem. O trabalho com a colagem abala a noção de identidade, de sistema, noções tão caras às obras de arte, até o seu questionamento mais radical com as vanguardas artísticas do início do século xx. Essa obra em colapso, fragmentada, deflagra a precariedade das regras artísticas, da distinção espacial entre o dentro e o fora, entre arte e vida, sonho e vigília, ou mesmo o limite entre o sagrado e o profano. É a perda da imagem hegemônica, o deslocamento da supremacia da constância da imagem e a incorporação da plasticidade, da sensorialidade e do caráter operatório no fazer artístico.

Todas essas questões levaram a abordagem do texto dramático de Picasso a mergulhar no levantamento de algumas características das obras de colagem do artista, que poderiam também servir à pesquisa como uma chave interpretativa para as imagens criadas por Picasso em sua peça. Assim, o artigo inicialmente mergulha na compreensão da ideia de colagem de Marjorie Perloff para nortear a reflexão.

A noção de colagem tornou-se central à pesquisa e o caminho de entrada para a análise da peça. Ao trabalhar com a ideia de colagem, as categorias de tempo e espaço tornam-se fundamentais para reflexão. Compreendida como malha de fragmentos deslocados, como composição de indícios contraditórios, a colagem altera a noção de totalidade, que passa a ser vista como materiais recortados em novas associações.

Marjorie Perloff, no capítulo intitulado «A invenção da colagem» de seu livro $O$ momento futurista, define o procedimento como «contraste de materiais diretamente empregados como coisas em justaposição aos elementos líricos» (Perloff, 1993: 102). Para a autora, um «jogo de diferenças» se estabelece, entre outros aspectos, através da separação do objeto de seu campo de origem e sua reativação em outro ponto. A colagem é compreendida como uma transplantação, uma readerência, uma citação, questionando a autoridade da assinatura. Segundo Perloff, a noção de colagem é entendida como perda de uma ordenação central, quebra das relações lógicas, a favor de relações de similaridade e equivalência:

Cada elemento citado quebra a continuidade ou linearidade do discurso e conduz necessariamente a uma dupla leitura: a do fragmento percebido em relação ao seu texto de origem, e a do mesmo fragmento como incorporado em um novo conjunto, uma totalidade diferente. O estratagema da colagem consiste também em nunca suprimir inteiramente a 
alteridade desses elementos reunidos em uma composição temporária. (Perloff, 1993: 103)

Uma imagem, portanto, relacionada à ideia de tempo, a elementos conflitantes em processo de operação. A imagem como uma montagem de tempos heterogêneos em obra.

Perloff analisa que na colagem cubista os fragmentos introjetados (selo postal, folha de jornal, corda de violão) mantêm a sua alteridade, ainda que ela esteja subordinada a uma nova totalidade. A autora analisa que nas colagens de Picasso a peça-colagem assume uma função oscilante formando, ao entrar em contato com os outros elementos, uma nova síntese, uma composição. Perloff, em seu ensaio, cita uma declaração de Picasso que revela o intuito do artista ao trabalhar com materiais deslocados de seu contexto:

A folha de jornal nunca foi usada a fim de se fazer um jornal. Foi usada para se tornar uma garrafa ou qualquer coisa desse tipo. Nunca foi usada literalmente, mas sempre como um elemento deslocado de seu significado habitual para outro significado. (Picasso apud Perloff, 1993: 133)

A questão apontada por Perloff da separação do objeto de seu campo de origem e sua reativação em outro lugar me interessa verificar, pois compreendo os elementos que compõem a cena no texto de Picasso, estruturados de forma a criarem sínteses constantes que imediatamente são desfeitas ao entrarem em contato com outros elementos. Esses elementos parecem ter sido deslocados de sua função habitual e reativados em outros contextos a partir do choque entre materiais heterogêneos.

Tendo em mente essas questões relativas à colagem, concentremos agora na análise da peça. O desejo pego pelo rabo foi escrita em 1941, durante o período em que Picasso viveu em Paris, em plena ocupação nazista. Nesta fase, foi proibido de expor seus trabalhos pelas autoridades alemãs e dedicou-se, entre outras experiências, a escrever o texto em questão. Ainda durante a guerra, a peça obteve uma leitura, ocorrida em 1944, na casa de seu amigo Michel Leris, diante de um público de amigos em que estavam presentes Jean-Paul Sartre, Simone de Beauvoir, Dora Maar, Albert Camus, Lacan, Georges Braque, Sabartés, entre outros.

A peça é dividida em seis atos, com um número de cenas variado em cada um. O primeiro e o segundo atos são compostos por duas cenas 
cada um deles, o terceiro ato é composto por três cenas e o quarto, quinto e sexto atos são compostos por apenas uma cena longa. Embora os personagens se mantenham durante toda a peça, as cenas são independentes umas das outras. A peça não possui uma narrativa linear. As constantes rupturas apresentadas no texto, que aparecem desde a sua estrutura até seus materiais narrativos, sugerem o choque e acentuam o caráter inorgânico da obra. ${ }^{1}$

Há uma clara vinculação entre o texto escrito por Picasso e um texto cênico proposto pelo autor que se estabelece no exercício de combinação dos diversos enunciados. Percebo em sua peça a estruturação de uma gigantesca partitura que combina o espaço, o texto verbal, as sonoridades, a luz e a performance do ator. As rubricas de Picasso são particularmente reveladoras. Em muitas delas é possível observar o autor dirigindo uma cena sem palavras e de teor plástico. Uma experiência de teatralidade ${ }^{2}$ vivenciada através de estímulos visuais e auditivos que convidam o leitor.

A tradução dessas fissuras na estrutura dramática do texto pode ser verificada em diversos aspectos da experiência artística, seja na aparente estaticidade da peça, que parece não avançar em termos dramáticos, e que pode ser percebida pelas repetições de falas e cenas, ou então na relação cada vez menos determinada entre a situação e a ação, exigindo uma reconstrução constante por parte do receptor. Esta cocriação do leitor/espectador é precipitada pela fragmentação da percepção que se dá em todos os níveis da estrutura narrativa, na linguagem, no uso da luz, da música ou mesmo na configuração dos personagens.

Os personagens são intrigantes e inconclusos. Seus nomes já são indícios desse fato: $\mathrm{O}$ Pé Grande, A Angústia Gorda e A Angústia Magra, A Ponta Redonda, Os Dois Totós, As Cortinas, A Cebola, A Torta,

1 Este conceito é aqui trabalhado a partir das noções de obra orgânica e inorgânica desenvolvidas por Peter Burger no livro A teoria da vanguarda. Procurando distingui-las, o autor define: «Num sentido geral, a obra de arte estabelece-se como unidade de generalidades e particularidades. Esta unidade, sem a qual é impossível conceber uma obra de arte, realiza-se, no entanto, de modos muito diferentes nas diversas épocas da evolução da arte. Nas obras de arte orgânicas (simbólicas) a unidade do geral e do particular verifica-se sem mediações; nas obras inorgânicas (alegóricas), pelo contrário, entre as quais se encontram as de vanguarda, existe mediação [...] A obra de vanguarda não nega a unidade em geral (se bem que os dadaístas o tenham tentado), mas um determinado tipo de unidade, a relação entre a parte e o todo característica das obras de arte orgânicas» (Burger, 1993: 101-102).

2 Patrice Pavis conceitua este termo como «aquilo que, na representação ou no texto dramático é especificamente teatral (ou cênico)», ou ainda, de forma mais específica, referindo-se à definição de Roland Barthes, «é uma espessura de signos e de sensações que se edifica em cena a partir do argumento escrito, é aquela espécie de percepção ecumênica dos artifícios sensuais, gestos, tons, distâncias, substâncias, luzes, que submerge o texto sob a plenitude de sua linguagem exterior» (Pavis, 2007: 372). 
O Silêncio, Sua Prima. Os próprios nomes dos personagens indicam seu caráter fragmentário. Eles são pedaços de corpos, sentimentos deslocados ou desdobrados, pedaços de objetos, legumes, frutas e animais destacados de seus ambientes. O duplo, o desmembramento de um personagem em dois, como é o caso de A Angústia Magra e A Angústia Gorda, por exemplo, acentua ainda mais a falta de singularidade dos objetos e pessoas retratadas.

Os corpos em pedaços como, por exemplo, O Pé Grande e A Ponta Redonda, e momentos de pura escatologia determinam uma presença corporal muito forte e violenta em meio à perda clara da ideia de sujeito e de subjetividade. $\mathrm{O}$ corpo, em várias passagens do texto, também se afigura como o lugar da dor. É um corpo partido, com tensões, que vivencia situações extremas como fome, frio, sede, calor e desejo.

Há no texto um claro caminho de substituição de uma visão mais concludente por uma percepção mais aberta e fragmentária. As estruturas produzidas através de todos os elementos propostos na peça são antes parciais que totais, enfatizando um inacabamento constitutivo. Como na forma de figurar seus personagens, através dos quais os seres e objetos se apresentam aos pedaços, fraturados, por meio de personagens que são apenas um pé, uma angústia dividida entre gorda e magra, um membro da família isolado, a prima, ou apenas a extremidade de alguma coisa, a ponta redonda.

A sensação de fragmentação parece corresponder às intromissões de planos notados nas obras cubistas e que se tornaram praticamente uma linguagem na modernidade. Essa nova forma de figuração determinou a multiplicação de experiências que atravessam e interrompem a narrativa, instauram uma superposição de tempos e espaços e alteram a noção de temporalidade. Na peça verificamos esses indícios através de vários aspectos, seja na composição dos personagens, nas mudanças de luz ou no uso da música. Há uma coexistência de tempos e espaços superpondo planos distintos, muitas vezes dentro de uma única cena.

A linguagem observa as mesmas noções de fragmentação, incompletude e jogo encontradas em todos os outros elementos do texto. A narrativa é breve, as cenas não se estendem muito. A linguagem não é referencial, não remete o leitor ou espectador a um universo distante da experiência cênica. Ela, ao contrário, é matéria podendo ser trabalhada concretamente através de seus ritmos, durações e sonoridades. Os diálogos em sua maioria são compostos por frases curtas e muitas vezes com repetição de termos e palavras. A essas frases curtas intercalam outras 
extremamente longas com um fluxo verbal que parece sublinhar sua busca de sentido e comunicabilidade.

O texto não apresenta o uso de letras maiúsculas no início das frases, de vírgulas ou de pontos finais. Frequentemente algumas frases do texto são separadas por travessões e a maioria das rubricas é indicada por parênteses. Todas essas opções não só conferem ritmo às palavras, como determinam um desenho à escrita da peça. Uma escrita como ato é configurada por Picasso ao aproximar sua escrita dramática à cênica, ao acreditar que as duas se dão de forma concomitante. Ele escreve a cena pensando-a no espaço, na relação com os demais elementos, fato que se confirma em suas rubricas. Quase não há interlocução, o discurso não se constrói plenamente, apontando para uma estrutura inconclusa, em que o jogo de associações, acumulações e oposições se torna o aspecto dominante de toda a narrativa.

Essas acumulações e rupturas provocam deslocamentos de sentido, criando tensões através do evidente rompimento com a linearidade do discurso. O fluxo narrativo cede lugar a uma experiência compósita estruturantes das obras de colagens cubistas.

O jogo de associações, repetições e contrastes estende-se também à cena. Planos se interpenetram, objetos, trechos musicais, referências a animais e pessoas se confundem num jogo de transformações permanente. Um espaço de sensações é criado pela introdução de experiências táteis, auditivas, olfativas, comestíveis e visuais. Todos os sentidos parecem conversar e, nesse contato, cria-se uma zona de atrito, um diálogo que também ajuda a romper com a noção de causalidade no interior das experiências cênicas ou mesmo entre as cenas, que assim ganham em independência. A ideia de colagem é constante e se estabelece através da rede de analogias e rupturas estruturadas pela linguagem e na tensão entre os diversos materiais, espacialidades e tempos diferentes que confluem nas cenas.

$\mathrm{Na}$ cena II do ato I, apresenta-se um momento no qual o caráter de colagem e a forte presença corporal tornam-se bem evidentes. A cena começa com uma rubrica que indica uma mudança de luz. Picasso sugere que seja uma «luz de tempestade». A cena segue com os personagens das Cortinas agitando-se e, no final de sua fala, indica que elas deveriam estar «rindo e peidando». A pequena fala dita por elas, aliás, o único momento falado da cena, é composto por um texto repleto de imagens contraditórias que se constroem e no instante seguinte se desfazem: 


\section{As Cortinas agitando-se}

Que tempestade que noite uma verdadeira certamente noite acariciante uma noite da China

Uma noite pestilenta em porcelana da China noite de tempestade em meu ventre incoerente (rindo e peidando) (Picasso, 1997: 21)

Após a fala das Cortinas, Picasso sugere, através da rubrica, a entrada da música $A$ dança macabra, de Saint-Saëns, e em seguida que «pés de chuva» comecem a cair e «fógos-fátuos» corram pelo palco.

Todo um universo externo à peça é convocado ao escutarmos a composição. Ao mesmo tempo em que a intromissão musical cria um choque ao nos remeter a uma dimensão externa à narrativa, a música, ao entrar em contato com as indicações de luz (fogos-fátuos) e as marcações cênicas (a agitação das Cortinas), cria uma lógica própria e estabelece um quadro polifônico, em que os diversos elementos, a princípio díspares, conversam e criam o ambiente desejado por Picasso.

Assim como na colagem, a experiência espacial é importante. Aqui também a luz se especializa através dos deslocamentos na cena e no ritmo dessa ocupação. Segundo a rubrica, os fogos-fátuos «correm» pelo palco, imprimindo um ritmo acelerado à situação, conferindo à luz uma pulsação e uma dimensão temporal experimentada no espaço. A luz ganha um valor ideográfico. Através de sua dimensão espacial e temporal ela ocupa a cena e a desenha, criando formas no tempo e no espaço.

Novamente o caráter de justaposição e colagem é operado. Seja no texto das personagens das Cortinas, através de imagens opostas e de ruptura, como «noite acariciante»e «noite pestilenta» ou na imagem de «porcelana da China»e «tempestade em meu ventre» que associamos ao ato de rir e peidar, seja na entrada da música de Saint-Saëns em meio ao espaço ficcional. Para completar, um jogo de linhas e planos se estabelece na cena com as sugestões da chuva e dos fogos que riscam o palco. A cena como um todo sugere o corte, o fracionamento inerente à colagem. A justaposição de elementos, o jogo de opostos, a velocidade em que a todo o momento a cena se transforma ao entrar em contato com um novo elemento proposto pelo artista, tudo isso parece criar uma associação entre o processo das colagens de Picasso e sua escrita dramatúrgica. Sensações orgânicas desordenadas e sem controle também se apoderam das personagens. É o corpo proclamando seus desejos que é apresentado por Picasso. 
Outro momento interessante pode ser verificado na cena II do ato II, onde novos personagens, elementos cênicos e fragmento musical são introduzidos e propostos ao lado de imagens corporais fortes:

\section{(mesmo cenário)}

Dois homens de cogula trazem uma banheira imensa cheia de espuma para o palco diante das portas do corredor depois de um fragmento de violino de A TOSCA do fundo da banheira saem as cabeças de Pé Grande a Cebola a Torta sua Prima a Ponta Redonda os dois Totós o Silêncio a Angústia gorda e a Angústia magra as Cortinas (idem, 26)

Nesta cena, temos uma enorme banheira cheia de espuma que atravessa o palco carregada por dois «homens de cogula» (homens de capuz) e de onde saem diversos personagens. A escolha de um objeto do cotidiano que se apresenta em lugares reservados e se caracteriza pelo peso, a imobilidade e o uso individual é tratado pela cena de forma móvel e coletiva desconstruindo um princípio de caracterização do objeto. Ao mesmo tempo em que nos lembramos do objeto banheira, ele se descaracteriza ao adquirir novas funções neste jogo de transformações e impermanências. A banheira, portanto, perde o seu caráter de imobilidade ao ser carregada pelos «homens de cogula» e seu uso individual, ao permitir que de dentro dela saiam as cabeças dos personagens O Pé Grande, A Cebola, A Torta, Sua Prima, A Ponta Redonda. As dimensões da banheira também são alteradas. Segundo a rubrica de Picasso, «dois homens de cogula trazem uma banheira imensa cheia de espuma». O objeto banheira foi redimensionado assumindo a condição de presença e ausência. Ela está presente enquanto signo banheira, mas metaforicamente transformada através das novas proporções adquiridas.

Um acúmulo de imagens sobrepostas é sugerido. No entanto, no jogo de justaposições, apenas partes dessas imagens tornam-se aparentes como, por exemplo, as cabeças dos personagens que têm seus corpos imersos na banheira, ou o fragmento de violino da «Tosca». A cena segue com uma brincadeira infantil de esconde-esconde e divertimentos sexuais:

\section{A Cebola}

Puta velha putinha 


\section{A Ponta Redonda}

Onde que você acha que está caro amigo em casa ou no bordel

\section{Sua Prima}

Se você continuar não tomo mais banho e vou embora

\section{A Torta}

Onde está meu sabonete meu sabonete meu sabonete

\section{O Pé Grande}

A malandra

\section{A Cebola}

É a malandra
A Torta
É bom esse sabonete cheira bem esse sabonete

\section{A Ponta Redonda}

Vou meter esse sabonete em você

\section{O Pé Grande}

Bela criança quer que eu a esfregue?

\section{A Ponta Redonda}

Que marafona (idem, 27)

Uma fala do personagem do Pé Grande parece bem reveladora da presença corporal e as suas conotações sexuais:

\section{O Pé Grande}

Você tem as pernas bem feitas o umbigo bem esculpido a cintura fina os seios perfeitos a arcada da sobrancelhas transtornante e sua boca é um ninho de flores suas ancas um sofá e o assento móvel de seu ventre um camarote nas touradas nas arenas de Nîmes suas nádegas um prato de cassoulet e seus braços uma sopa de barbatana de tubarão e seu e seu ninho de andorinhas ainda o fogo de uma sopa de ninhos de andorinhas mas meu repolho meu pato e meu lobo fico transtornado fico transtornado fico transtornado (idem, 27) 
O corpo feminino é associado a imagens de comida, a animais e a objetos dando livre curso à imaginação. A antiga imagem sublime do corpo da mulher amada é substituída por imagens grotescas, muitas vezes humorísticas e absolutamente concretas, ligadas a objetos do cotidiano, a imanência.

A cena termina com mais uma explosão de imagens, através da introdução de mais dois novos personagens, e uma situação de forte presença corporal é construída sem nenhuma relação prévia com a anterior, criando uma experiência sensorial e instaurando uma temporalidade diversa:

os dois Totós com latidos gritantes lambem todos cobertos de espuma pulam para fora da banheira e os banhistas vestidos como todos na época saem da banheira só a Torta sai completamente nua mas de meias-carregam cestas cheias de iguarias de garrafas de vinho de toalhas de guardanapos de facas de garfos-preparam um belo piquenique-chegam coveiros com caixões onde enfurnam todos-pregam-nos e levam-nos embora (idem, 28-29)

O corpo humano rebaixado a alimento a ser saboreado por animais propõe uma imagem inquietante de pura inversão. São os animais que saboreiam os corpos humanos. No instante seguinte, essa imagem é rapidamente substituída por outra onde os personagens fazem um piquenique se alimentando e bebendo. Na sequência, esses personagens são enterrados vivos em caixões por coveiros. Vida e morte se misturam. Novamente os limites são postos em xeque e uma nova lógica se impõe baseada nos sentidos. Cabe também ao espectador desfrutá-las e decifrá-las a partir de suas vivências e memórias. $O$ espectador é convocado continuamente a operar em si mesmo essas imagens em constante transformação.

Duas cenas propõem claramente uma experiência sensorial e de aproximação entre sua escrita dramática e cênica, no caso a experiência dos cabelos e a experiência com o odor. Na cena III do ato III, Picasso sugere que as personagens da Torta, a Prima e as duas Angústias cortem as mechas do cabelo do Pé Grande e logo após começam a ser chicoteadas «por chicotes de sol» através das lâminas das persianas. Esta cena, segundo Picasso, deve durar quinze minutos: 
cabeça como um queijo da Holanda chamado «Tête de mort» (caveira) através das lâminas das persianas da janela chicotes de sol começam a bater nas quatro mulheres sentadas ao redor de Pé Grande (idem, 41)

A cena longa oferece aos atores e espectadores uma experiência física de contato corporal forte, de desconstrução e profanação da figuração tradicional da imagem do homem. A sugestão é que o cabelo do personagem seja realmente cortado em cena e suas mechas jogadas no chão. Enquanto as mulheres raspam a cabeça do personagem, elas apanham com chicotes, numa cena de sadismo, brutalidade e prazer.

Na cena I do ato IV, o autor propõe um silêncio de alguns minutos e uma experiência com odores:

grande silêncio de alguns minutos durante os quais no buraco do ponto sobre um bom fogo e numa grande caçarola irá ver-se e ouvir-se e cheirar-se fritar batatas em óleo fervente cada vez mais a fumaça das batatas vai encher a sala até a asfixia completa (idem, 47)

Além do tempo também pensado como acumulação e sobreposição, pois é uma temporalidade nova que é estabelecida, a sobrecarga de imagens persiste aliada agora à justaposição dos sentidos. $\mathrm{O}$ autor indica que a cena será preenchida pelo cheiro das batatas sendo fritas e pela obstrução da visão através da fumaça, e por fim pela «asfixia completa» advinda da fritura. Novamente outros sentidos são convocados. A visão claramente cede lugar à experiência com os odores rompendo o limite do palco unindo público e atores numa mesma experiência comunal. As cenas apresentam um texto com forte caráter plástico, que se constrói no tempo através de ritmos e durações, completando-se ao ser ouvido ou ser silenciado. As cenas foram pensadas para o palco. Uma escrita que é ação desde sua organização no texto como um desenho, até sua finalização no palco.

No ato III, na já comentada cena III, na qual as personagens A Torta, A Angústia Gorda e A Angústia Magra tiram tesouras de seus bolsos e cortam os cabelos do personagem O Pé Grande, verifica-se outra forma de jogo com a sonoridade. No decorrer da ação, as personagens dialogam através de brincadeiras sonoras com as palavras e as vogais. No texto original, acentos ortográficos como o trema e o acento grave foram colocados por Picasso sobre as vogais, sugerindo, além de uma investigação sonora, uma pesquisa plástica. As palavras deixam de remeter a um 
significado para se tornarem mais um material a ser manipulado. Elas assumem um valor ideográfico. São desenhadas no texto. A tradução da peça para o português, de Marina Appenzeller, não trabalhou com a acentuação gráfica sugerida por Picasso em seu manuscrito. A tradução portuguesa de Vitor Silva Tavares também optou por não acentuar as vogais. Segue o trecho em francês para análise do trabalho gráfico e sonoro das palavras no texto:

\author{
La Tarte \\ aï aï aï aï aï aï aï \\ La Cousine \\ aï aï aï aï
}

\title{
L'Angoisse Maigre
}

aï aï aï aï aï

\section{L'Angoisse Grasse}

à à à à à à à à à à

(et ça continue pendant un bon quart d'heure)

Le Gros Pied (en rêve)

L'os de La moelle charrie dês glaçons

\section{La Cousine}

oh qu'il est beau aï aï aï qui aï oh qui aï est aï aï aï aï bob o

\section{L'Angoisse Grasse}

a a a bo a a bo bo

\section{La Tarte}

aï aï jê l'aime aï aï aime bo bo aï aï aï l'aime aï aï bo bob o

(elles sont couvertes de sang et tombent évanouies par terre)

O uso dos acentos gráficos pode ser um exemplo do valor ideográfico das palavras. Neste mesmo trecho do texto original em francês, Picasso trabalha a palavra bonito (beau) apenas através de sua sonoridade. Ele estabelece uma brincadeira sonora com a sílaba «bo»e a repete várias vezes. 
O sentido da palavra é substituído por sua importância sonora. Na tradução portuguesa de Vitor Silva Tavares, o tradutor procurou manter a brincadeira com a sonoridade traduzindo «beau» por «belo». Assim, a sonoridade da palavra é buscada através da sílaba «bé» de belo e «bébéloé» de «belo é».

Retiro da tradução de Vitor Silva Tavares o mesmo trecho da peça para verificação:

\section{A Torta}

Ai ai ai ai ai ai ai...

\section{A Prima}

Ai ai ai ai...

\section{A Angústia Magriça}

Ai ai ai ai ai...

\section{A Angústia Gorducha}

A a a a a a a a...

E continuam assim durante um bom quarto de hora.

O Patorra, em sonhos

No osso de tutano escorregam caramelos.

\section{A Prima}

Oh que belo é! Ai ai ai... que ai... oh! Que ai ai bé ai ai ai... béloé.

\section{A Angústia Gorducha}

A a bé a a bébéloé

\section{A Torta}

Ai ai Eu amo-o Ai ai amo bébéloé ai ai ai amo-o ai ai bébébéloé

Estão cheias de sangue e caem por terra desmaiadas

As Cortinas, abrindo as pregas face a esta cena desastrosa, imobilizamo despeito por trás da imensidão do tecido desdobrado 
Na tradução para o português brasileiro de Marina Appenzeller, a palavra «bonito» não foi trabalhada em sua sonoridade. Ela se manteve.

O desenho gráfico criado por Picasso através do uso dos acentos ortográficos não foi repetido em nenhuma dessas duas traduções que eu tive acesso. $\mathrm{O}$ uso do acento grave e do trema cria ritmos, sonoridades às sílabas, além de sugerir desenhos às palavras através de imagens de pontilhados (trema) e de riscos e linhas (crase) às frases.

Os jogos sonoros criados através do uso de onomatopeias, repetições de fonemas e palavras, das durações sonoras ou mesmo da colagem de fragmentos musicais, são alguns dos recursos dramatúrgicos utilizados por Picasso para criar a imagem complexa, dissonante, multitemporalizada e descontínua que analiso em sua forma de figurar as suas sensações e ideias. As sonoridades são vivenciadas como acontecimento através dos jogos de palavras, dos jogos sonoros, das vozes alternadas, pelo seu entendimento como materialidade a ser trabalhada no espaço e no tempo. Elas são compreendidas como materiais em constante processo de mutação e são experimentadas no tempo produzindo durações. São também experiências espaciais com valor ideográfico, uma vez que constroem desenhos sonoros no texto dramático e na cena ao serem pronunciadas ocupando o espaço cênico.

A mistura, a sobreposição, a descontinuidade provocando a manipulação de estágios diferentes de realidade, levada ao extremo com a introdução de objetos do mundo na obra artística, podem ser percebidas em diversos exemplos em sua peça. A conjunção de planos é compreendida em sua escrita dramática, através de um trabalho que conjuga os contrastes fortes com o efeito de grandes explosões, que ajudam a fraturar todo o texto e estabelecer seu constante processo de desconstrução e reconstrução. Essa aparência de obra em permanente processo operatório observada em seu texto dramático só se estrutura por conta da larga experiência de Picasso em suas colagens. Estas obedecem ao mesmo trabalho de adição, justaposição e manipulação temporal.

Em colagens como Copo e garrafa de Suze, de 1912, ou Natureza-morta com cadeira de palha, do mesmo ano, é possível verificar o jogo de manipulação exercido pelo artista com os objetos reais, como notícias de jornais e cordas, manipulando estágios diferentes de realidade. As cordas que envolvem a colagem e servem de moldura, a imagem da palhinha ou as várias citações do jornal na colagem Copo e garrafa de Suze, criando uma «polifonia de vozes», como analisa Rosalind Krauss em seu livro Os papéis de Picasso, removem as fronteiras entre o simulado e o real, 
construções arbitrárias se justapõem e se unem. Perloff, analisando as obras de colagem, sugere que os papéis colocados uns sobre os outros na superfície opaca subvertem todas as relações convencionais de figura e fundo ao justapor itens do mundo. Páginas de jornal, ilustrações, letras, criariam uma superfície enigmática.

Os corpos desmembrados e muitas vezes sugerindo um aspecto de dor também são todo o tempo aparentes na peça. A primeira cena do ato II, por exemplo, inicia-se com apenas os pés dos convidados aparecendo de forma visível. Eles sentem muita dor e reclamam das frieiras.

\author{
Ato II, cena I \\ Um corredor no Hotel \\ Os dois pés de cada conviva estão \\ Diante das portas de seus quartos \\ Contorcendo-se em dor
}

Os Dois Pés do Quarto N. III

Minhas frieiras minhas frieiras minhas frieiras

\title{
Os Dois Pés do Quarto N. V
}

Minhas frieiras minhas frieiras

Os Dois Pés do Quarto N. IV

Minhas frieiras minhas frieiras

\section{Os Dois Pés do Quarto N. II}

Minhas frieiras minhas frieiras minhas frieiras As portas transparentes iluminam-se e sombras dançantes de cinco macacos comendo cenouras aparecem

Escuridão total (idem, 25)

Todos os personagens da peça estão deslocados de seu universo original que lhes configuraria inteireza e singularidade. Objetos como as Cortinas ou partes de objetos como a Ponta Redonda dividem as cenas com animais duplicados, como os dois Totós ou os cinco macacos dançarinos. Sentimentos e elementos comestíveis ganham vida trabalhados como contrastes, criando choques e intercambiando realidades.

Quanto às portas, essas são iluminadas de forma que a luz as atravesse. É somente a partir dessa luz transversal que vemos as sombras de 
cinco macacos atrás da porta, numa clara alusão às técnicas do teatro de sombras. As portas por um momento deixam de ser portas, tornam-se molduras, palcos para aparição das sombras. A condição icônica de porta se desorganiza. O jogo de significados se instala e no instante seguinte se transforma. O que é fundo e o que é figura no jogo entre a transparência e o opaco, entre o claro e o escuro? A cena termina com a indicação de uma «escuridão total». A luz é trabalhada atravessando o palco, criando linhas perpendiculares que riscam a cena dividindo-a em áreas iluminadas e escuras, determinando jogos de claro e escuro, alternâncias entre luminosidade e obscuridade. Recortes espaciais e volumes são criados através da oscilação entre pouca ou nenhuma luz. A imagem dos pés dá lugar à figura dos cinco macacos. As variações de sombras provocam um efeito de densidade e transparência, permeabilidade e impermeabilidade que sentimos através da luz que atravessa as portas.

Através do jogo de reversibilidade, o processo de transformações se estabelece, somatório de destruições obtidas pelo entendimento das figuras como unidades à disposição. É uma imagem portadora de latência e energética onde a mais simples figuração nunca é sossegada.

A noção de disjunção estruturada através da experiência da colagem parece ser o motor principal da arte de Picasso e talvez possa ser entendida a partir da compreensão que em Picasso tudo pode ter uma leitura iconográfica, tudo pode ser transformado em imagem. Para tanto, o espectador precisa ser instigado, e assim como nos quadros, a peça também nos convida a decifrar seus diversos «enigmas» em meio às suas construções imagéticas. A noção de colagem está presente nos diálogos, nas sugestões cenográficas, nas rubricas, nos jogos de claro e escuro ou no entendimento dos personagens como fragmentos, como partes que se compõem a todo instante.

Na linguagem, os substantivos se sucedem num processo de acumulação em que uma imagem é imediatamente substituída por outra. Nas rubricas, a indicação do uso de elementos como a iluminação, recursos sonoros e de objetos cenográficos também se organiza na cena através da lógica da justaposição dos elementos, criando muitas vezes o choque entre os enunciados.

Assim, compreendo que a linguagem no texto de Picasso necessita encarnar-se fisicamente. As palavras ocupam o espaço cênico através da criação de sonoridades e temporalidades. O texto de Picasso é, portanto, fruto dessas inúmeras experimentações artísticas ocorridas principalmente a partir do início do século $\mathrm{xx}$, que encontrou, entre tantas 
possibilidades de expressão experimentadas nesse período, o surrealismo como campo de investigação.

A inter-relação entre o discurso dramático e o pictórico na obra dramatúrgica de Pablo Picasso $O$ desejo pego pelo rabo reside na compreensão dessa estreita correlação entre as artes. O texto escrito em 1941, portanto muito tempo depois de inúmeras experiências radicais em todas as áreas artísticas, se apresenta como mais um campo de experimentação em que é possível estabelecer um diálogo entre diversas linguagens: a pintura, a escultura, o desenho, a música, o teatro e a performance.

Perceber essa inter-relação possibilitou uma compreensão mais ampla da estruturação das imagens em seu texto dramático. A peça de Picasso, escrita em 1941, se constrói através de uma linguagem híbrida fruto de quase meio século de experiências artísticas vivenciadas por Picasso nas diversas linguagens artísticas que experimentou.

\section{REFERÊNCIAS BIBLIOGRÁFICAS}

BURGER, Peter (1993), «A obra de arte vanguardista», in Teoria da vanguarda, Lisboa, Vega.

KRAUSS, Rosalind (2006), Os papéis de Picasso, São Paulo, Iluminuras.

PAVIS, Patrice (2007), Dicionário de teatro, São Paulo, Perspectiva.

PERLOFF, Marjorie (1993), «A invenção da colagem», in O momento futurista, São Paulo, Edusp.

PICAss o, Pablo (1997), O desejo pego pelo rabo, trad. Maria Appenzeller, Porto Alegre, L\&PM.

- (1975), O desejo agarrado pelo rabo. As quatro meninas. Teatro, trad. Vitor Silva Tavares e Aníbal Fernandes, Lisboa, \&etc.

- (2008), Le désir attrapé par la queue, France, Gallimard.

\footnotetext{
ANA LÚCIA BRASIL MALECHA

Licenciada em Educação Artística pela Universidade Federal do Estado do Rio de Janeiro (UNIRIO), 2007, e bacharel em Artes Cénicas pela UNIRIO, 1994, é mestre em Artes Cénicas pela UNIRIO, 2012. Possui Curso Profissionalizante de Interpretação pela Escola de Teatro Martins Pena, 1987.
} 